\title{
Russeting and Relative Growth Rate Are Positively Related in 'Conference' and 'Condo' Pear
}

\author{
Johannes Daniel Scharwies ${ }^{1}$, Eckhard Grimm, and Moritz Knoche ${ }^{2}$ \\ Institute for Horticultural Production Systems, Leibniz University Hannover, \\ Herrenhäuser Straße 2, D-30419 Hannover, Germany
}

Additional index words. cuticle, fracture, microcrack, periderm, Pyrus communis, strain, stress

\begin{abstract}
Russeting is an important surface disorder in fruit and mechanical growth stresses, among other factors, are considered causal in russet induction. To test this hypothesis, fruit development and russeting were monitored on a whole fruit level and also in the calyx, cheek, and neck region of developing 'Conference' and 'Condo' pear fruit (Pyrus communis L.). To quantify growth, the pear fruit was geometrically modeled as approximating to half of a prolate spheroid for the calyx region and two truncated cones for the cheek and neck regions, respectively. Mass and surface area of 'Conference' and 'Condo' fruit increased in a single sigmoidal pattern with time. Fruit volume, determined by buoyancy, using a hydrostatic balance, and the Archimedes' principle was closely related to that predicted by the model from fruit geometry. Growth rates of surface area in 'Conference' and 'Condo' peaked at $\approx 90$ and 100 days after full bloom (DAFB), respectively, and were highest in the calyx followed by the cheek and neck regions. Relative growth rates, calculated by dividing growth rates by the absolute surface area present at that time, were at maximum during early development and thereafter continuously declined. In general, relative growth rates were highest for the cheek region, intermediate in the calyx, and lowest for the neck. 'Conference' fruit were always more russeted than 'Condo' with russeting generally decreasing from calyx to cheek and neck. Furthermore, russeting increased rapidly in 'Conference' during early development until $\approx 70$ DAFB, particularly in the calyx and cheek regions and, to a lesser extent, in the neck region. There was little change in russeting after $\approx 70$ DAFB. Plotting rates of russeting vs. relative growth rates in surface area indicate a positive and common relationship across regions where russeting increased when relative growth rates exceeded $0.03 / \mathrm{day}$. Thus, differential growth rates between regions within 'Conference' or 'Condo', but not across the two cultivars, accounted for topical differences in russeting.
\end{abstract}

Russeting is an important surface disorder in smooth-skinned cultivars of apple (Malus $\times$ domestica Borkh.) and pear that results in significant economic losses. The brownish, dull appearance of russeted fruit is unattractive to the consumer who prefers smoothskinned fruit. In russeting, the primary skin, comprising cuticle, epidermal, and hypodermal cell layers, is replaced by secondary dermal tissue called periderm. This periderm forms in the hypodermis (Meyer, 1944). The periderm consists of meristematic phellogen that produces phelloderm cells toward the inner and phellem cells toward the outer side by cell division (Esau, 1969). Suberin deposition on the cell walls of the phellem is responsible for the brownish appearance of russeted peel.

Received for publication 14 Feb. 2014. Accepted for publication 12 Apr. 2014.

We thank Friederike Schroeder and Simon Sitzenstock for technical support and Drs S.D. Tyerman and B.P. Khanal for very helpful comments on an earlier version of this manuscript.

${ }^{1}$ Present address: School of Agriculture, Food and Wine, Waite Research Institute, University of Adelaide, Urrbrae, SA 5064, Australia.

${ }^{2}$ To whom reprint requests should be addressed; e-mail moritz.knoche@obst.uni-hannover.de.
Microscopic fractures ("microcracks") in the fruit surface are considered to be the first visible symptom in russeting (Faust and Shear, 1972a, 1972b). Factors causing microcracking often stimulate russeting. Such factors include high humidity, prolonged surface wetness, exposure to freezing temperatures, mechanical injury, and colonization with certain microorganisms (Faust and Shear, 1972a; Gildemacher et al., 2006; Knoche and Grimm, 2008; Simons and Chu, 1978). Mechanical growth stresses of the expanding surface provide the driving force for microcracking (Curry, 2009; Skene, 1980, 1982). Supporting evidence for this relationship comes from the observation that mechanical growth stresses are at maximum during early fruit development when fruits are particularly sensitive to russeting (Knoche et al., 2011; Wertheim, 1982). From this we hypothesize that the incidence of russeting will be higher on surfaces subjected to high relative growth rates and vice versa. Pear fruit is a particularly suitable crop to test this hypothesis because it offers contrasting surface growth rates and relative growth rates in the surface area within the same fruit, thereby normalizing for fruit-to-fruit variability.

The objective of our study, therefore, was to test this hypothesis using two cultivars of pear, which differ in susceptibility to russeting; 'Conference' is classified as being highly susceptible, whereas 'Condo' is intermediate susceptible. The fruit was partitioned into three regions of contrasting shape and a geometrical model was developed to quantify growth rates of the fruit surface. These were related to the development and final incidence of russeting in those regions during fruit growth and at maturity.

\section{Materials and Methods}

Plant material. Fruit of pear ('Conference', 'Condo', grafted on Quince C, Cydonia oblonga MILL.) were obtained from the experimental orchard of the Leibniz University Hannover in Ruthe (lat. $52^{\circ} 14^{\prime} \mathrm{N}$, long. $9^{\circ} 49^{\prime}$ E), Germany. Trees were cultivated according to current standards of integrated fruit production. Fruits were hand-thinned to one fruit per cluster at $18 \mathrm{DAFB}$

Monitoring fruit growth. Calibrated images of fruits $(n=5)$ were taken (E520; Olympus Europa) at six dates between 25 and 144 DAFB. Two images per fruit and date were taken in longitudinal view but perpendicular to each other after rotating the fruit by $90^{\circ}$. At the same time, a different set of fruit was sampled $(\mathrm{n}=5$ per sampling date with six dates per cultivar), wrapped in a moist paper towel to reduce water loss, transferred to the laboratory, and held for a maximum of $2 \mathrm{~d}$ at $5.5{ }^{\circ} \mathrm{C}$ and $80 \%$ relative humidity. Likewise, images of these fruits were taken as described previously. Fruit mass, volume, and density were determined (BP211D, YDK01; Sartorius, Göttingen, Germany). The volume was recorded by measuring the fruit's buoyancy, using a hydrostatic balance, and the Archimedes' principle (up to 67 DAFB: YDK01; Sartorius; for stages greater than 67 DAFB a custom-built construction was used).

To calculate growth rates in different regions of the fruit surface, a geometrical model of the pear was developed. This model comprised half of a prolate spheroid at its distal portion ("calyx") and two truncated cones, referred to as "cheek" and "neck," at the stem end (Fig. 1). The diameter of the calyx corresponded to the fruit's maximum equatorial diameter $\left(\boldsymbol{d}_{\max }\right)$ and the height $\left(\boldsymbol{h}_{\text {calyx }}\right)$ to the polar radius of the prolate spheroid. The cheek segment had a height of $\boldsymbol{h}_{\text {cheek }}$ and distal and proximal diameters of $\boldsymbol{d}_{\max }$ and $\boldsymbol{d}_{A}$, respectively. Preliminary analyses established that $\boldsymbol{d}_{\max } / 2$ was a good estimate for $\boldsymbol{h}_{\text {cheek }}$ (J.D. Scharwies, unpublished data). Therefore, it was used subsequently. The neck was approximated by the second truncated cone with the height $\boldsymbol{h}_{\text {neck }}$. Because it was difficult to quantify the diameter of the stem end of the neck $\left(\boldsymbol{d}_{C}\right)$, the mean diameter of the cone $\boldsymbol{d}_{B}$ determined at $\boldsymbol{h}_{\text {neck }} / 2$ was measured instead and $\boldsymbol{d}_{C}$ calculated according to $\boldsymbol{d}_{C}=2 \cdot \boldsymbol{d}_{B}-\boldsymbol{d}_{A}$. The values of $\boldsymbol{d}_{\max }, \boldsymbol{h}_{\text {calyx }}$, $\boldsymbol{d}_{A}, \boldsymbol{h}_{\text {neck }}, \boldsymbol{d}_{A}$, and $\boldsymbol{d}_{B}$ were quantified by image analysis (Cell ${ }^{\wedge} \mathrm{P}$; Olympus Europa). From these dimensions, total surface area, total volume per fruit, and surface areas in calyx, cheek, and neck regions were calculated for 
fruits of which images were taken in the orchard. The precision of this model was assessed by comparing the volume calculated from fruit dimensions using the model to the measured volume of the same fruit.

Quantifying russeting. Russeting was quantified at maturity in 'Conference' and 'Condo'. Additionally, the progression of russeting during the course of fruit development was quantified in 'Conference' only. Mature 'Conference' and 'Condo' fruit were peeled, and the flattened peel was spread on a glass plate. The russeted portion of the peel was painted using acrylic paint (cobalt blue, product ID 23443; H. Schmincke, Erkrath, Germany). This was necessary to enhance the contrast between russeted and non-russeted portions of the fruit surface for image analysis. Subsequently, images of the peel were taken (Kodak Easy Share P880; Kodak, Stuttgart, Germany) and total peel area, russeted, and non-russeted area quantified on an individual fruit basis ( $\mathrm{n}=109$ to 110$)$.

Russeting of developing 'Conference' fruit was analyzed using a modified procedure. Two calibrated images in longitudinal view, but perpendicular to each other, were taken of eight developing pears sampled at nine dates between 25 and 144 DAFB. These images of the fruits were divided into calyx, cheek, and neck segments using the pear model described previously (Fig. 1). The perimeters of each segment were traced by digital image analysis

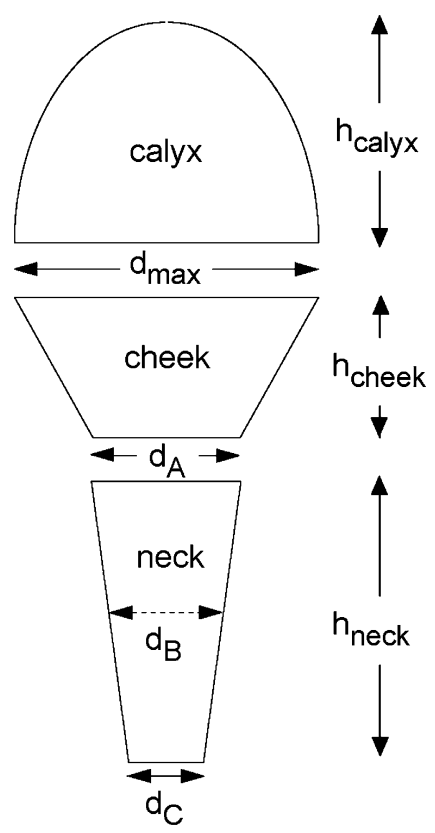

Fig. 1. Sketch of the geometric model used to describe the shape of 'Conference' and 'Condo' pear. The model consists of a prolate spheroid describing the calyx and two truncated cones for the cheek and neck. The calyx has a diameter $\boldsymbol{d}_{\max }$ and a polar radius $\boldsymbol{h}_{\text {calyx }}$, the truncated cheek cone has diameters of $\boldsymbol{d}_{\max }$ and $\boldsymbol{d}_{A}$, and the height $\boldsymbol{h}_{\text {cheek }}$. The truncated cone describing the neck is defined by the diameters $\boldsymbol{d}_{A}$ and $\boldsymbol{d}_{C}$ and the height $\boldsymbol{h}_{\text {neck. }}$. The diameter $\boldsymbol{d}_{C}$ was calculated from $\boldsymbol{d}_{C}=2 \cdot \boldsymbol{d}_{B}-\boldsymbol{d}_{A}$ with diameter $\boldsymbol{d}_{B}$ at $\boldsymbol{h}_{\text {neck }} / 2$. For further details, see "Materials and Methods." and partitioned into perimeter sections tracing russeted and non-russeted portions of the fruit perimeter. Their respective length was quantified and the portion of russeted and nonrusseted perimeter section as percentage of the total perimeter calculated. Preliminary experiments established that the mean russeted perimeters (perimeter in percent) and the mean russeted area (area in percent) were linearly related and essentially identical [perimeter $(\%)=0.93( \pm 0.02) \cdot$ area $(\%), R^{2}=$ $0.989, P<0.001, \mathrm{n}=20]$. The mean russeted areas were quantified as described previously.

Data analysis. Unless stated otherwise, data are presented as mean \pm SEM. Where not shown, error bars are smaller than data symbols. Analysis of variance (ANOVA) and linear regression analysis were performed using SAS (Version 9.1.3; SAS Institute, Cary, NC). For ANOVA, russeting data were arcsine-transformed. Diagrams and curve fits were generated using SigmaPlot 10.0 (Systat Software, Erkrath, Germany).

\section{Results}

The mass of 'Conference' and 'Condo' pear fruits increased in a single sigmoidal pattern with time (Fig. 2). There was little difference between the mass determined directly by weighing the fruit and that predicted from fruit density and volume using dimensions quantified by image analysis and the pear model described in Figure 1. In both cultivars, the fruit mass predicted by the model at maturity was slightly lower than the mass determined directly. This resulted from a slight $(5.5 \%$ to $1.3 \%)$ underestimation of fruit volume, because slopes of regression lines, fitted through plots of predicted volumes using the pear model vs. volumes measured using Archimedes' principle, were $0.945 \pm 0.007\left(R^{2}=0.998, P<0.001, \mathrm{n}=30\right)$ and $0.987 \pm 0.005\left(R^{2}=0.999, P<0.0001\right.$, $\mathrm{n}=27$ ) for 'Conference' and 'Condo', respectively, (Fig. 2, insets). Overall, mass of 'Conference' pear fruit was significantly lower compared with 'Condo' at maturity $(147.3 \pm 4.4 \mathrm{~g}$ vs. $211.5 \pm 15.1 \mathrm{~g})$. Fruit density decreased in both cultivars during the course of fruit development, probably as a result of development of the seed cavities (Fig. 2A-B).

Total surface area and the areas of calyx, cheek, and neck regions increased in a single sigmoidal pattern with time in both 'Conference' and 'Condo' (Fig. 3A-B). Based on the pear model (Fig. 1), the surface area of the calyx region was largest followed by the cheek and the neck.

Growth rates in total surface area and in the areas per region peaked in 'Conference' at $\approx 90$ DAFB and in 'Condo' at 100 DAFB (Fig. 3C-D). In both cultivars, growth rates were highest in the calyx followed by the cheek and neck.

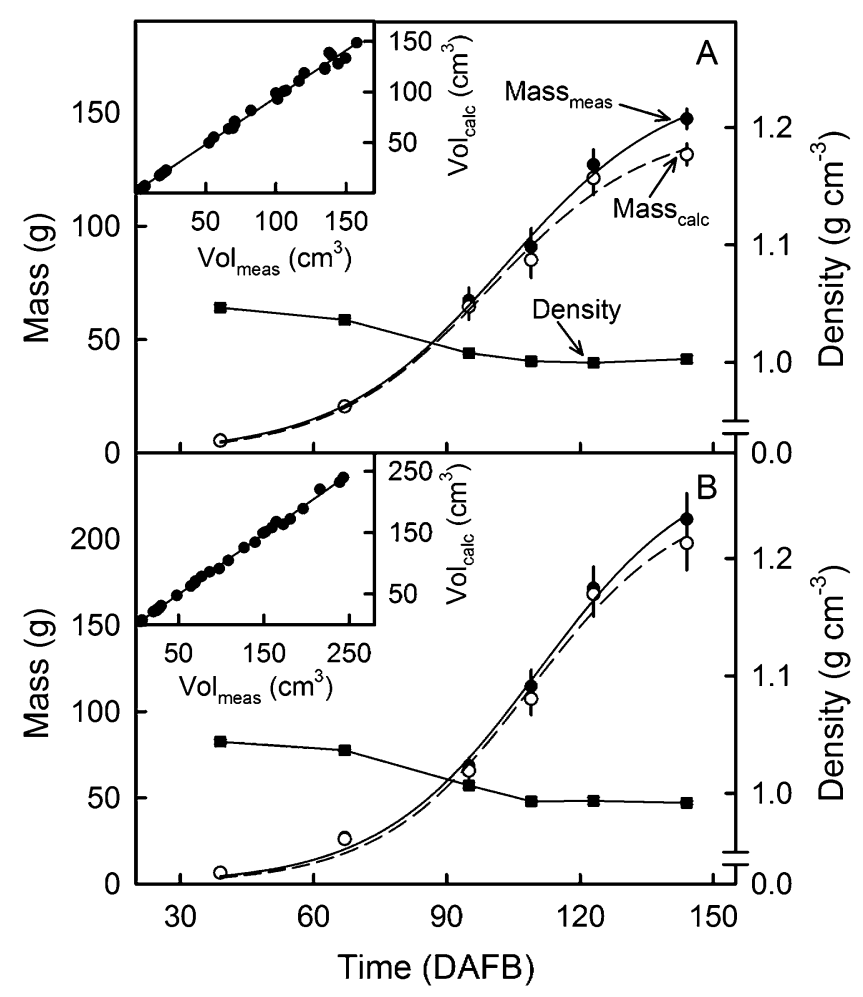

Fig. 2. Developmental time course of change in fruit fresh weight and density of developing 'Conference' (A) and 'Condo' pear (B). Data represent means \pm SE of five replicates. The X-axis scale is in days after full bloom (DAFB). (Insets) Plots of the predicted volume $\left(\mathrm{Vol}_{\text {calc }}\right)$ vs. the volume measured as the fruit's buoyancy using a hydrostatic balance $\left(\mathrm{Vol}_{\text {meas }}\right)$. The $\mathrm{Vol}_{\text {calc }}$ was calculated using dimensions quantified by image analysis based on images of developing fruit and the pear model described in Figure 1. Slopes of the regression lines were $0.945 \pm 0.007\left(R^{2}=0.998, P<0.001, \mathrm{n}=30\right)$ and $0.987 \pm$ $0.005\left(R^{2}=0.999, P<0.0001, \mathrm{n}=27\right)$ for 'Conference' and 'Condo', respectively. 
Relative growth rates calculated by dividing growth rates in surface area (square centimeter per day) by absolute surface area present at that time (square centimeter) were at maximum during early development and continuously declined thereafter (Fig. 3E-F). In both cultivars, relative growth rates were highest in the cheek region, intermediate in the calyx, and lowest in the neck. These differences between regions decreased and essentially disappeared during the course of development Fig. 3E-F).

Comparing the percentage of russeted surface area at maturity revealed that 1) 'Conference' fruit was always more russeted than 'Condo'; and 2) russeting of 'Conference' decreased from calyx to cheek and neck (Table 1). Similar data were obtained for 'Condo'. In this cultivar, however, there was no difference in russeting between the cheek and neck, probably as a result of an overall lower incidence of russeting.

Russeting was also dependent on the developmental stage in 'Conference' (Fig. 4A). The percentage of russeted surface increased rapidly between 25 and 70 DAFB, particularly in the calyx and cheek region and to a markedly lesser extent in the neck region. For the mature pear, russeting averaged $85.5 \% \pm 4.2 \%, 69.3 \% \pm 4.2 \%$, and $25.5 \% \pm$ $4.0 \%$ for the calyx, cheek, and neck region, respectively. From the measured changes of russeting over time, rates of russeting were calculated and plotted against the relative growth rates in surface area for the different regions of the fruit surface (Fig. 4B). This analysis revealed a common positive relationship between rates of russeting and relative growth rates valid across the calyx, cheek, and neck regions of 'Conference' pear fruits
(Fig. 4B). Rates of russeting were low when relative growth rates were low (less than $0.03 / \mathrm{d})$. However, russeting increased in all regions at relative growth rates greater than 0.03/d (Fig. 4B).

\section{Discussion}

Our data established that 1) the calyx and cheek were generally more russeted as compared with the neck; and 2) differences in russeting between the more spherical regions (calyx and cheek) and the more elongated neck region were accounted for by relative growth rates in surface area in these regions. Most russeting occurred during early development when relative growth rates were high. In the more susceptible cultivar, Conference, russeting increased rapidly up to $\approx 70 \mathrm{DAFB}$, which coincides with high relative growth rates (greater than $0.03 / \mathrm{d}$ ). From $\approx 70 \mathrm{DAFB}$ onward, russeting remained constant and relative growth rates had decreased to below $0.03 / \mathrm{d}$. These observations are largely consistent with the view that high relative growth rates cause high mechanical growth stresses, which, in turn, provide the driving force for formation of microcracks that may trigger periderm formation (Faust and Shear, 1972a, 1972b; Knoche et al., 2011; Wertheim, 1982).

Although the previously described hypothesis explains the higher susceptibility of calyx and cheek region as compared with the neck and that of the young vs. the maturing pear, it does not account for differential russeting of the calyx and cheek or that of 'Conference' and 'Condo'. The calyx region has a lower relative growth rate than the cheek yet is more russeted (Table 1; Fig. 4). Conversely, 'Conference' and 'Condo' have

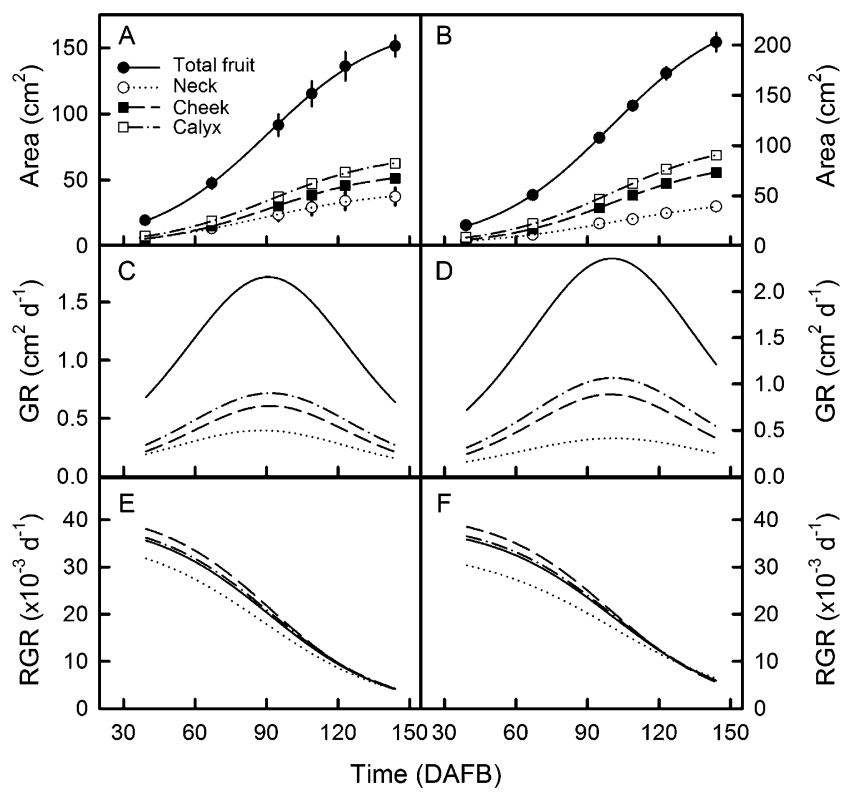

Fig. 3. Time course of change in surface area (A-B), surface growth rate (GR; C-D), and the relative growth rate (RGR; E-F) of developing 'Conference' $(\mathbf{A}, \mathbf{C}, \mathbf{E})$ and 'Condo' $(\mathbf{B}, \mathbf{D}, \mathbf{F})$. The fruit surface area was calculated from dimensions determined on images by image analysis using the pear model described in Figure 1. The RGR (in 1/day) was calculated by dividing growth rate (in $\mathrm{cm}^{2} \cdot \mathrm{d}^{-1}$ ) by the surface area (in $\mathrm{cm}^{2}$ ) present at that time. The X-axis scale is in days after full bloom (DAFB). The data in $\mathbf{A}$ and $\mathbf{B}$ represent means $\pm \mathrm{SE}$ of five replicates.

similar relative growth rates, but 'Conference' is markedly more russeted ( $68.8 \%$ vs. $9.5 \%$ of the surface russeted in 'Conference' and 'Condo'; Table 1). Thus, additional factors must be involved.

Theoretically, failure of the cuticle can also result from mechanical stress concentration. Stress concentration, in turn, may occur 1) at a whole fruit level, e.g., caused by curvature of the fruit surface (Considine and Brown, 1981); 2) at a tissue level, e.g., as a consequence of lenticels (Brown and Considine, 1982); 3) at a cellular level, e.g., caused by irregular size and shape of cells of the fruit skin as proposed by Eccher (1975); and, possibly, 4) at a molecular level, e.g., resulting from strain amplification or strain fixation as a result of wax deposition within the cuticle polymer (Khanal et al., 2013). In addition, extended periods of surface wetness were shown to induce microcracking (Knoche and Grimm, 2008) and russeting in apple (Creasy, 1980; Knoche et al., 2011). Of these factors, stress concentration caused by curvature and prolonged wetness duration may account for the higher russet susceptibility of the calyx as compared with the cheek despite slightly lower relative growth rates. Young pear fruit remain in an upright position until $\approx 60 \mathrm{DAFB}$ (range, 53 to $67 \mathrm{DAFB}$ ) and rain water collects in the flower remnants of the calyx and the developing calyx cavity. When turning to the hanging position, pending water droplets collect at the calyx end. Thus, the calyx region is subject to extended periods of surface wetness as compared with the cheek and neck, where wetness duration is shorter as a result of runoff.

The differential russet susceptibility of 'Conference' and 'Condo' is unlikely to be caused by stress concentration on a whole fruit or a tissue level because 1) fruit shape and relative growth rates were largely similar; and 2 ) there was no clear association of russet initiation and lenticels. Also, there was no indication for differential wetness duration between the two cultivars. At present, it is not known whether triggers on a cellular and/or molecular level are causal.

The fruit model used in our study deserves some additional comment. The model used here provided a satisfactory description of developing 'Condo' and 'Conference' pear. It differs from the single cone plus spherical cap model proposed by Martins et al. (2008). The latter model was not suitable for the

Table 1. Percentage of russeted fruit surface area in mature 'Conference' pear $(n=110)$ and 'Condo' $(\mathrm{n}=109){ }^{\mathrm{z}}$

\begin{tabular}{llr}
\hline & \multicolumn{2}{c}{ Russeted area [mean \pm SE $(\%)]$} \\
\cline { 2 - 3 } Position & Conference & Condo \\
\hline Neck & $42.8 \pm 2.3 \mathrm{a}^{\mathrm{y}}$ & $8.7 \pm 0.8 \mathrm{a}$ \\
Cheek & $75.9 \pm 2.0 \mathrm{~b}$ & $6.9 \pm 0.5 \mathrm{a}$ \\
Calyx & $87.6 \pm 2.3 \mathrm{c}$ & $13.0 \pm 0.8 \mathrm{~b}$ \\
Total & $68.8 \pm 1.5$ & $9.5 \pm 0.4$ \\
\hline
\end{tabular}

${ }^{z}$ The percentage russeting per region was quantified on flattened peel by image analysis (see also "Materials and Methods").

'Mean separation within cultivars, Tukey's Studentized range test $(P<0.05)$. 

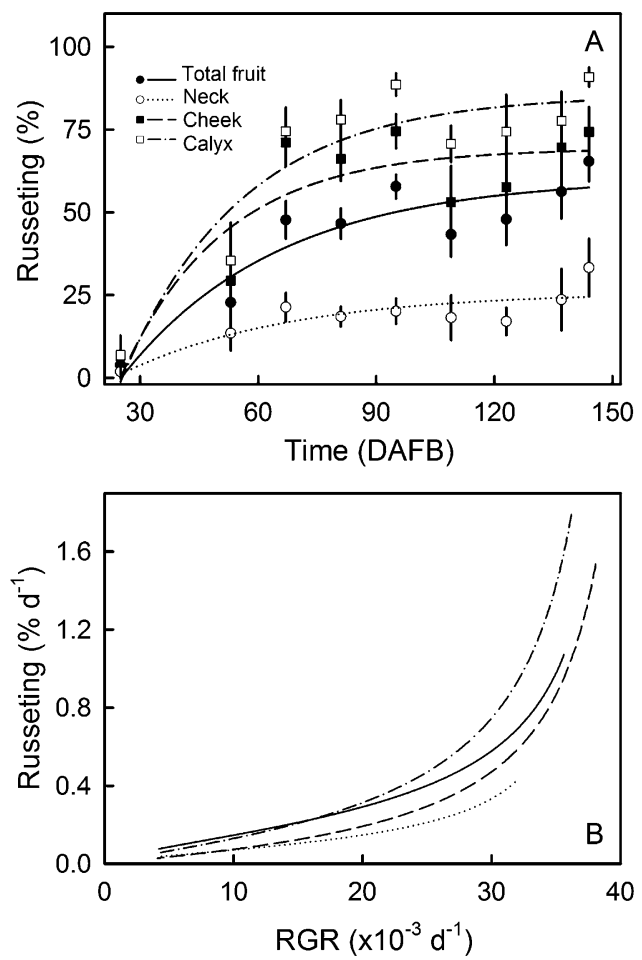

Fig. 4. (A) Time course of change in russeting in calyx, cheek, and neck regions of developing 'Conference' pear. The X-axis scale is in days after full bloom (DAFB). The fruit surface was partitioned into calyx, cheek, and neck segments using the pear model described in Figure 1. Data represent means \pm SE of eight replicates. For details, see "Materials and Methods." (B) Relationship between the rate of russeting and the relative growth rate in surface area in calyx, cheek, and neck regions. The rate of russeting was calculated as slope of the time course of russeting depicted in Figure $4 \mathrm{~A}$; the relative growth rates in surface area were taken from Figure 3E.

shape of the two cultivars used in the present study. Also, the model by Martins et al. (2008) would have been unable to predict (relative) growth rates in different regions of the fruit, i.e., neck, cheek, and calyx. Clearly, some systematic deviations between the predicted and measured volumes remained, particularly as the fruit matured. These, however, were small and considered insignificant given the objective of our study. A higher precision would have required more input data for an improved description of the fruit shape (Jancsók et al., 2001).

\section{Conclusion}

Our data establish a close relationship between an increase in surface area and the incidence of russeting in developing pear fruit. This relationship is based on 1) the coincidence of russeting and rapid surface expansion during early development; and 2) topical differences in russeting that reflect differences in rates of surface expansion. Both observations provide further support to the hypothesis that russeting is a repair mechanism initiated by failure of the fruit surface resulting from mechanical growth stresses.

\section{Literature Cited}

Brown, K. and J. Considine. 1982. Physical aspects of fruit growth-Stress distribution around lenticels. Plant Physiol. 69:585-590.

Considine, J. and K. Brown. 1981. Physical aspects of fruit growth-Theoretical analysis of distribution of surface growth forces in fruit in relation to cracking and splitting. Plant Physiol. 68:371-376.

Creasy, L.L. 1980. The correlation of weather parameters with russet of 'Golden Delicious' apples under orchard conditions. J. Amer. Soc. Hort. Sci. 105:735-738.

Curry, E.A. 2009. Growth-induced microcracking and repair mechanism of fruit cuticles. Proc. SEM Annu. Conf., Soc. Expt. Mechanics, Albuquerque, NM. 23 Dec. 2013. <http://sem-proceedings.com/09s sem.org-SEM-2009-Ann-Conf-s078p04-Growthinduced-Microcracking-Repair-MechanismsFruit-Cuticles.pdf $>$.

Eccher, T. 1975. Influenza di alcuni fitormoni sulla rugginosita della 'Golden Delicious'. Rivista Dell’Ortoflorofrutticoltura Italiana 59:246-261.

Esau, K. 1969. Pfanzenanatomie. Gustav Fischer Verlag, Stuttgart, Germany.

Faust, M. and C.B. Shear. 1972a. Russeting of apples, an interpretive review. HortScience 7:233-235

Faust, M. and C.B. Shear. 1972b. Fine structure of the fruit surface of three apple cultivars. J. Amer. Soc. Hort. Sci. 97:351-355.

Gildemacher, P., B. Heijne, M. Silvestri, J Houbraken, E. Hoekstra, B. Theelen, and T. Boekhout. 2006. Interactions between yeasts, fungicides and apple fruit russeting. FEMS Yeast Res. 6:1149-1156.

Jancsók, P.T., L. Clijmans, B.M. Nicolai, and J. De Baerdemaeker. 2001. Investigation of the effect of shape on the acoustic response of 'Conference' pears by finite element modelling. Postharvest Biol. Technol. 23:1-12.

Khanal, B.P., E. Grimm, S. Finger, A. Blume, and M. Knoche. 2013. Intracuticular wax fixes and restricts strain in leaf and fruit cuticles. New Phytol. 200:134-143.

Knoche, M. and E. Grimm. 2008. Surface moisture induces microcracks in the cuticle of 'Golden Delicious' apple. HortScience 43:1929-1931.

Knoche, M., B.P. Khanal, and M. Stopar. 2011. Russeting and microcracking of 'Golden Delicious' apple fruit concomitantly decline due to gibberellin A4+7 application. J. Amer. Soc. Hort. Sci. 136:159-164.

Martins, J.M.S., A.R. Rosa, S. Martins, D. Fialho, and J. Abreu. 2008. Modelling the shape and growth of a pear. Acta Hort. 800:331-337.

Meyer, A. 1944. A study of the skin structure of 'Golden Delicious' apples. Proc. Amer. Soc. Hort. Sci. 45:105-110.

Simons, R.K. and M.C. Chu. 1978. Periderm morphology of mature 'Golden Delicious' apple with special reference to russeting. Sci. Hort 8:333-340.

Skene, D.S. 1980. Growth stresses during fruit development in Cox's Orange Pippin apples. J. Hort. Sci. 55:27-32.

Skene, D.S. 1982. The development of russet, rough russet and cracks on the fruit of the apple Cox's Orange Pippin during the course of the season. J. Hort. Sci. 57:165-174.

Wertheim, S.J. 1982. Fruit russeting in apple as affected by various gibberellins. J. Hort. Sci. $57: 283-288$. 